\title{
CIDADANIA NO CONTEXTO DOS CATADORES AUTÔNOMOS DE MATERIAIS RECICLÁVEIS
}

\section{CITIZENSHIP IN THE CONTEXT OF COLLECTORS INDEPENDENT RECYCLABLE MATERIALS}

Data de submissão: 12/01/2015

Aceite: $27 / 10 / 2015$

Hugo Manuel Bastos ${ }^{1}$

Geraldino Carneiro De Araújo

\section{RESUMO}

Este artigo tem como objetivo analisar a cidadania de catadores autônomos, trabalhadores de baixa renda e, por isso, discriminados pela sociedade em que vivem. Para isso, procedeu-se a uma pesquisa descritiva, com uma abordagem qualitativa, a partir de um estudo de caso realizado em uma colônia de catadores no município de Paranaíba, Mato Grosso do Sul. Como fontes de evidência, foram realizadas entrevistas semiestruturadas com dez catadores autônomos, abordando oito temáticas diferentes: caracterização da cooperativa; vida pessoal do catador cooperado; adesão por este trabalho; meio ambiente; saúde e riscos; dificuldades da profissão; melhorias no trabalho; e visão sobre quem é o catador. Dentre os resultados, destacam-se o preço que os atravessadores pagam pelos materiais como a principal dificuldade da profissão e a importância que a organização em forma de cooperativa poderia ter, uma vez que fortaleceria a identidade dos catadores.

Palavras-chave: Cidadania. Catadores de Materiais. Economia Solidária.

\footnotetext{
${ }^{1}$ Possui graduação em andamento em Administração pela Universidade Federal De Mato Grosso Do Sul, UFMS. Campo Grande. Mato Grosso do Sul. Brasil. E-mail: hugo.bastos@outlook.com

${ }_{2}^{2}$ Possui graduação em Administração pela Faculdades Integradas Rui Barbosa, FIRB, mestrado em Agronegócios pela Universidade Federal de Mato Grosso do Sul, UFMS e doutorado em Administração pela Universidade Nove de Julho, UNINOVE. Atualmente é professor no curso de Administração na UFMS/CPAR - Universidade Federal de Mato Grosso do Sul Câmpus de Paranaíba. Pranaíba. Mato Grosso do Sul. Brasil. E-mail: geraldino.araujo@gmail.com
} 


\begin{abstract}
This article aims to analyze the citizenship of autonomous pickers, low-income workers and so discriminated by society in which they live. For it, proceeded descriptive research directed to a qualitative approach, from a case study performed in a colonia of pickers of municipality of Paranaiba, Mato Grosso do Sul. As evidence sources, were carried out semi-structured interviews with ten autonomous pickers, addressing eight issues: cooperative characterization; personal life of picker; accession in this work; environmental; health and risk; difficulties of the profession; improvements at work and vision about who is the picker. Among the results, we highlight the price that pay middlemen those materials as the main difficulty of the profession and the importance what an organization in cooperative, that can strengthen the identify of pickers.
\end{abstract}

Keywords: Citizenship. Scavengers of Materials. Solidarity Economy.

\title{
1 INTRODUÇÃO
}

Entende-se que a cidadania é fundamental para a sobrevivência dos seres humanos, pois é por seu intermédio que os direitos fundamentais são garantidos (DALLARI, 2004). Marshall (1967) explicita que a cidadania é um status para aqueles que são membros de uma comunidade, de modo que todos que possuem esse status são iguais em termos de direitos e obrigações, ainda que algumas classes, como a de catadores de materiais recicláveis, por exemplo, nem sempre tenham esses direitos respeitados.

A Política Nacional de Resíduos Sólidos (PNRS), estabelecida por meio da Lei $\mathrm{n}$. o $12.305 / 2010$, visa fortalecer os direitos dos catadores e das cooperativas de reciclagem, prevê, dentre outros fatores, a destinação correta dos materiais recicláveis (BRASIL, 2010). Tal legislação impulsiona o retorno dos produtos às empresas de origem e delega ao poder público a obrigação de realizar planos para o gerenciamento dos resíduos sólidos. Além disso, a classe de catadores, a partir de 2002, passou a ter sua profissão reconhecida pela Classificação Brasileira de Ocupações (CBO) como Catador de Material Reciclável. Kirchner, Saidelles e Stumm (2009) explicam que os catadores estão buscando uma forma de se inserirem no mundo social e do trabalho, em que desempenham uma função muito relevante para a sociedade e o meio ambiente.

$\mathrm{O}$ trabalho de reciclagem de materiais vem sendo realizado de forma amadora pelos catadores de materiais recicláveis. A presença das cooperativas de reciclagem nesse processo é ainda modesta, fruto da própria gestão e infraestrutura precarizadas, deixando, assim, para os catadores de materiais recicláveis todos os méritos pelo reaproveitamento de resíduos (MAGERA, 2008). Michels et al. (2004) ressaltam que os catadores têm um papel fundamental dentro da cadeia dos resíduos sólidos, pois são eles que retiram do meio ambiente grande quantidade destes materiais, fomentando a indústria de recicláveis.

Diante disso, considerando os catadores autônomos, ou seja, aqueles que não estão organizados de forma coletiva, este estudo se propõe a analisar o exercício da cidadania no contexto dos catadores de materiais recicláveis.

\section{REVISÃO BIBLIOGRÁFICA}

Neste tópico, são discutidos o contexto dos catadores de materiais recicláveis e a questão da cidadania. 


\subsection{Catadores de materiais recicláveis}

A precarização da relação de trabalho está presente nas sociedades capitalistas em vários níveis, ocasionando exclusão social e, consequentemente, fragilização da cidadania nacional (KIRCHNER; SAIDELLES; STUMM, 2009). Nesse contexto, é importante discutir o direito do trabaIhador no que se refere à reestruturação do contrato de trabalho, à flexibilização dos horários, ao questionamento de direitos sociais, à condição de trabalhador, dentre outros aspectos. Tornar-se catador é fonte de dignidade e modo legítimo de obter renda. É uma profissão que faz do excluído um trabalhador inserido no mundo do trabalho, diferenciando-o do mendigo, por exemplo. Porém, a inclusão desses catadores no mercado de trabalho em meio a condições inadequadas, com um grau elevado de periculosidade e insalubridade, com ausência total de garantias trabaIhistas e sem reconhecimento algum perante a sociedade (MEDEIROS; MACÊDO, 2006).

Godoy (2005) ressalta que os catadores são um grupo de trabalhadores presente em todos os grandes centros mundiais, o que evidencia o caráter global da exclusão social. O número crescente desses profissionais representa a busca de meios de sobrevivência de uma parcela da população que, por vários motivos, não encontra outro caminho a não ser o da coleta de materiais recicláveis, os quais, muitas vezes, estão misturados ao lixo comum e até mesmo contaminados.

Os catadores de materiais recicláveis vivem em uma condição de pobreza singular. Além de possuírem poucos recursos para sobreviverem como todas as populações pobres, estão sob o estigma da sujeira, por sempre estarem em contato com o lixo. Nesse sentido, observa-se que os catadores desempenham suas atividades em condições extremas, sofrem preconceitos e possuem baixo reconhecimento do papel que representam na economia e no meio ambiente, embora tenham a profissão reconhecida e sejam resguardados por um comitê específico (MEDEIROS; MACÊDO, 2006).

Kirchner, Saidelles e Stumm (2009) argumentam que os catadores buscam uma forma de inserção no mundo social e do trabalho, realizando uma atividade relevante para a sociedade e o meio ambiente. Os catadores de materiais recicláveis normalmente optam pela profissão por estarem desempregados, uma vez que, por sua idade, condição social e baixa escolaridade, não encontram lugar no mercado formal de trabalho. Michels et al. (2004) explicam que os catadores exercem um papel fundamental dentro da cadeia dos resíduos, pois são responsáveis pela grande diminuição do acúmulo de resíduos sólidos e por agilizarem o escoamento dos materiais, fomentando a indústria da reciclagem. Separando o material, eles retiram do meio ambiente quantidades significativas de resíduos sólidos para a reciclagem industrial.

Para Medeiros e Macêdo (2006), embora a profissão de catador possa ser reconhecida pela sociedade como um trabalho digno, não há uma aceitação atualmente. O motivo seria a precariedade a que as pessoas se sujeitam para coletar o "lixo" que a população produz, sendo vistos como catadores de lixo e não de materiais recicláveis.

Gonçalves et al. (2013) expõem que os catadores de materiais recicláveis eram reconhecidos como um grupo excluído ou marginalizado, sendo confundidos, muitas vezes, com moradores de rua. Contudo, hoje contam com políticas públicas de inclusão social do governo federal, tendo sido reconhecidos, em 2002, pela CBO. O código 5192-05 regulamenta a profissão de catador de material reciclável e estabelece que esse profissional é responsável por coletar o material reciclável e reaproveitável, vender o material coletado, selecionar o material coletado, preparar o material para expedição, administrar o trabalho e trabalhar com segurança, dentre outras atividades (BRASIL, 2014).

Para Gouveia (2012), os catadores são considerados os protagonistas da indústria de reciclagem, pois detêm posição fundamental na gestão de resíduos sólidos. Estes grupos vêm 
atuando de modo informal ou organizados em cooperativas e associações e, até mesmo antes das definições de políticas públicas para a gestão de resíduos sólidos no país, vêm realizando um trabalho de grande importância ambiental, colaborando significantemente para o retorno de diversos tipos de materiais para o ciclo produtivo, gerando economia de energia e de matéria-prima e evitando, assim, que tais materiais sejam destinados a aterros.

Visto que os catadores de materiais recicláveis são, por diversas vezes, excluídos e marginalizados, torna-se importante, neste artigo, discutir as questões acerca da cidadania.

\subsection{Cidadania}

A cidadania pode ser compreendida a partir de vários pontos de vista. Dallari (2004) expõe que a cidadania é um aglomerado de direitos que concede à pessoa a chance de participar ativamente da vida e do governo de seu povo. Quem não possui cidadania está marginalizado ou até mesmo excluído da vida social e da tomada de decisão.

Para Coutinho (1999), a cidadania é a conquista de alguns indivíduos, ou de todos os indivíduos, que se apropriam dos bens socialmente criados, bem como a capacidade de atualizarem todas as potencialidades de realização humana abertas pela vida social em cada contexto histórico. A cidadania não é dada aos indivíduos de uma vez para sempre, não é algo que vem de cima para baixo, mas é resultado de uma luta constante, travada quase sempre a partir de baixo, das classes subalternas, implicando um processo histórico de longa duração. Grechoniak e Bordignon (2011) conceituam a cidadania como o respeito e envolvimento das decisões de determinada sociedade, de modo a garantir melhorias na sua própria vida e na vida de outros. Ou seja, é uma agregação de direitos e obrigações à que uma pessoa se sujeita em relação à comunidade que habita. Sua concepção está ligada ao exercício de direitos políticos, sociais e civis.

Marshall (1967) ressalta que a cidadania exige um elo de natureza diferente, isto é, um sentimento de participação em uma comunidade, que pode ser baseado na lealdade a uma civilização formada de homens livres, compenetrados de direitos e protegidos por uma lei comum. Seu desenvolvimento é incitado tanto pela luta de adquirir tais direitos quanto pelo gozo destes quando adquiridos.

A esse respeito, Severino (2000) ressalta que uma estrutura social em que o poder é mais justo na sua distribuição consiste na condição básica para os homens se humanizarem, ou seja, a condição básica para a cidadania. No seu sentido mais restrito, a cidadania reporta-se ao gozo dos direitos políticos e sociais, embora não se limite a eles. A cidadania formal, de acordo com Rodrigues (2006), é definida como a condição de membro de um estado-nação democrático que, em função disso, é portador de direitos políticos.

Dallari (2004) menciona que um cidadão é aquele que está vinculado à ordem jurídica de um estado, seja pelo local do nascimento, pela descendência ou por outros fatores, dependendo das leis de cada estado. Esse vínculo significa que o cidadão terá todos os direitos que a lei certifica aos cidadãos daquele estado, tendo também o direito de receber proteção de seu estado se estiver em território estrangeiro. Marshall (1967) afirma que a cidadania é um status concedido para aqueles que são membros integrais de uma comunidade, aos quais são delegados certos direitos e obrigações.

Com base no que foi apresentado, pode-se afirmar que cidadania é uma agregação de direitos e obrigações que um indivíduo tem com a sociedade em que vive, para que ela possa garantir o bem-estar desse indivíduo e de todos que ali habitam. Entretanto, nem sempre uma sociedade é justa com seus indivíduos, ainda que estes tenham conquistado seus direitos perante a lei e a comunidade. Os catadores de materiais recicláveis são um exemplo de pessoas descriminadas pela sociedade. 
Para Soares (s/d), a cidadania e os direitos da cidadania dizem respeito a determinada ordem jurídico-política de um país ou estado, em que uma Constituição determina e garante quem é cidadão e que direitos e deveres terá em função de uma série de variáveis, como idade, estado civil, sanidade física e mental, o fato de estar ou não em dívida com a justiça penal etc. Ressalta, ainda, que os direitos do cidadão e a própria ideia de cidadania não são universais, uma vez que estes são fixos a uma ordem jurídico-política fixa.

Outro ponto a ser abordado, conforme Tenório e Rozenberg (1997), consiste no fato de que a participação social e na cidadania se referem à apropriação pelas pessoas do direito de construção democrática do seu próprio destino. Esta é caracterizada pela organização coletiva dos participantes e pela oportunização da abertura de espaços de discussão dentro e fora dos limites da comunidade, de definição de propriedades, de preparação de estratégias de ação e de estabelecimento de canais de diálogo com o poder público, por exemplo.

Uma vez discutidos o contexto dos catadores de materiais recicláveis e as definições acerca da cidadania, a partir daqui são apresentados alguns estudos realizados que trataram da cidadania no contexto dos catadores de materiais recicláveis. Considerado neste estudo como uma das pesquisas teórico-empíricas mais relevantes para este artigo, Rios (2008) estudou a cidadania de catadores de materiais recicláveis sob o ponto de vista da vida pessoal do catador, abordando questões como a opção por este trabalho, o envolvimento com o meio ambiente, a saúde, os riscos e os aspectos socioeconômicos.

Gomes (s/d), tendo como base uma pesquisa desenvolvida no Aterro Metropolitano de Jardim Gramacho, de Duque de Caxias, Rio de Janeiro, analisou a questão dos resíduos sólidos e da cidadania por meio do processo de construção da identidade social a partir da prática cooperativa dos catadores, levando em conta o perfil dos catadores, sua identidade, a exclusão social e as práticas cooperativistas. Dias (2002), com o artigo intitulado "Lixo e cidadania: os impactos da política de resíduos sólidos de Belo Horizonte no mundo do trabalho do catador da ASMARE", examinou os impactos de um projeto de coleta seletiva em parceria com uma associação de catadores, abordando, para isso, a rotina dos catadores e aspectos ambientais.

Com base em um diagnóstico socioambiental realizado com os catadores do lixão municipal de Maceió, Alagoas, Stroh e Santos (2007) discutiram a precarização e insalubridade do trabalho do catador. No Quadro 1, exposto a seguir, apresenta-se o tema dos estudos teórico-empíricos levantados.

1) Caracterização do local da pesquisa:

2) Perfil do catador:

3) Adesão ao trabalho de catador:

4) Meio ambiente:

5) Saúde e riscos:

6) Dificuldades da profissão:

7) Melhorias no trabalho:

8) Visão sobre quem é o catador:

Quadro 1 - Categorias dos estudos teórico-empíricos sobre a cidadania dos catadores
Fonte: elaborado pelos autores.

É importante salientar que o exercício da cidadania extrapola estes oito itens do Quadro 1. Entretanto, são estes os considerados no contexto dos catadores de materiais recicláveis dos estudos aqui levantados.

Gomes (s/d), Stroh e Santos (2007);

Gomes (s/d), Dias (2002), Rios (2008);

$$
\text { Rios (2008); }
$$

Dias (2002), Stroh e Santos (2007), Rios (2008);

Stroh e Santos (2007), Rios (2008);

Dias (2002), Stroh e Santos (2007), Rios (2008); Gomes (s/d), Rios (2008); e, Gomes (s/d), Rios (2008). 


\section{PROCEDIMENTOS METODOLÓGICOS}

Esta pesquisa é descritiva, de modo que, conforme Collis e Hussey (2005), descreve o comportamento dos fenômenos, sendo usada para identificar e coletar informações sobre as características de determinado problema ou questão, podendo ser simples e/ou complexos (COOPER; SCHINDLER, 2011). Neste estudo, utilizou-se uma abordagem qualitativa. Duarte (2002) afirma que as pesquisas qualitativas exigem a realização de entrevistas quase sempre longas e semiestruturadas. Cooper e Schindler (2011) mencionam que a pesquisa qualitativa é um conjunto de técnicas interpretativas que buscam descrever, decodificar, traduzir e apreender o significado, e não a frequência, de certos acontecimentos.

Caracterizada como um estudo de caso, esta pesquisa foi desenvolvida em uma "Colônia de Catadores", em Paranaíba, Mato Grosso do Sul. Yin (2010) expõe que o estudo de caso é uma pesquisa empírica que analisa um fenômeno contemporâneo em profundidade e em seu contexto de vida real, principalmente quando os limites entre o fenômeno e o contexto não são visivelmente evidentes. O loca escolhido para estudo foi identificado a partir de uma consulta no Controle de Vetores do município, que considera o bairro como sendo de alto risco, uma vez que concentra grande número de catadores que acumulam materiais ao redor das casas.

Duarte (2002) afirma que o ato primordial de pesquisas qualitativas seria a definição de critérios para a seleção dos sujeitos que vão compor o universo de investigação, pois eles interferem diretamente na qualidade das informações e é a partir destas que será possível construir uma análise e chegar a uma compreensão mais ampla do problema delineado. Os sujeitos da pesquisa foram dez catadores autônomos, escolhidos aleatoriamente na "Colônia de Catadores" mencionada.

$\mathrm{O}$ instrumento de coleta de dados utilizado foi um roteiro semiestruturado de entrevista. O roteiro foi baseado no Quadro 1 deste artigo. Nesse sentido, nesta pesquisa foram definidas as seguintes categorias de análise: 1) caracterização da "Colônia de Catadores"; 2) perfil do catador cooperado; 3) adesão ao trabalho de catador; 4) meio ambiente; 5) saúde e riscos; 6) dificuldades da profissão; 7) melhorias no trabalho; e 8) visão sobre quem é o catador.

A técnica de tratamento dos dados ocorreu por meio da análise de conteúdo. Para Moraes (1999), a análise de conteúdo pode ser constituída como uma metodologia de pesquisa que é usada para descrever e interpretar o conteúdo de toda classe de documentos e textos. Auxilia a interpretar as mensagens e atingir um entendimento de seus significados em um nível que vai além de uma leitura comum.

\section{ANÁLISE DOS RESULTADOS}

A seguir, são discutidas as oito categorias quanto à cidadania dos catadores autônomos a partir do estudo de caso realizado.

\subsection{Caracterização da "Colônia de Catadores"}

O Controle de Vetores do município de Paranaíba tem um cadastro dos catadores autônomos de materiais recicláveis. Para este órgão, as residências desses catadores são pontos estratégicos que precisam de supervisão contínua, uma vez que os materiais coletados ficam amontados ao redor das casas, podendo tornar-se criadouros de vetores. Foram identificados vários endereços, todos na periferia do município, embora houvesse concentração de catadores em alguns bairros. 
O bairro selecionado para análise, como citado, localiza-se na periferia, é de difícil acesso e não tem estrutura básica (asfalto e rede de esgoto). O local foi denominado como "Colônia de Catadores" pelos pesquisadores, tendo em vista a proximidade entre os catadores, a presença marcante dos materiais próximos às casas e a cultura local estabelecida.

Outras características foram identificadas durante as entrevistas, tais como: o aproveitamento dos materiais coletados utilizados em sua função original, adaptados e/ou desmontados; as condições precárias de trabalho, em especial do carrinho/carroça dos catadores; a questão da pobreza; os problemas de saúde; e o descaso do poder público com o bairro e os catadores.

\subsection{Vida pessoal do catador cooperado}

Neste estudo, foram entrevistados dez catadores, cujo perfil é apresentado a seguir, no Quadro 2.

\begin{tabular}{|c|c|c|c|c|c|c|c|c|c|}
\hline 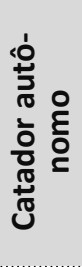 & $\begin{array}{l}\frac{0}{0} \\
\frac{\pi}{0}\end{array}$ & $\begin{array}{l}\text { 인 } \\
\stackrel{ }{\mathbb{U}}\end{array}$ & $\begin{array}{l}\frac{0}{0} \\
\mathbb{N} \\
\frac{N}{0} \\
0 \\
\frac{0}{0} \\
\frac{\mathbb{T}}{4}\end{array}$ & $\begin{array}{l}\text { o } \\
\text { 立 } \\
\text { o } \\
\text { o }\end{array}$ & 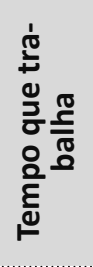 & 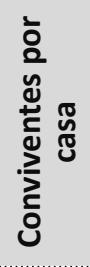 & 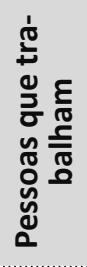 & 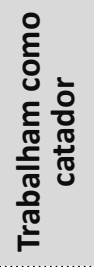 & 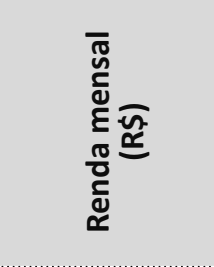 \\
\hline A & 51 & $M$ & Sim & 3 & 2 & 3 & 1 & 1 & Não informou \\
\hline B & 55 & $\mathrm{~F}$ & Não & 3 & 3 & 2 & 2 & 2 & 151 a 300 \\
\hline C & 52 & $M$ & Não & 2 & 12 & 2 & 1 & 1 & Menos de 150 \\
\hline D & 70 & $M$ & Não & 3 & 20 & 5 & 3 & 3 & 451 a 600 \\
\hline $\mathrm{E}$ & 75 & $M$ & Não & 7 & 15 & 4 & 2 & 1 & Acima de 751 \\
\hline $\mathrm{F}$ & 57 & $M$ & Não & 1 & 1 & 2 & 2 & 2 & 301 a 450 \\
\hline G & 60 & $M$ & Não & - & 1 & 4 & 2 & 1 & 451 a 600 \\
\hline $\mathrm{H}$ & 46 & $\mathrm{M}$ & Sim & 8 & 17 & 5 & 2 & 1 & Acima de 751 \\
\hline 1 & 49 & $\mathrm{~F}$ & Não & 8 & 7 & 4 & 3 & 2 & 301 a 450 \\
\hline $\mathrm{J}$ & 63 & $M$ & Não & 3 & 3 & 2 & 2 & 2 & 151 a 300 \\
\hline
\end{tabular}

Quadro 2 - Perfil dos catadores autônomos entrevistados

Fonte: dados da pesquisa de campo.

A maioria dos trabalhadores é do sexo masculino e não alfabetizada. A idade média destes trabalhadores é de 58 anos, que trabalha, em média, há oito anos na profissão e têm uma renda média mensal que gira em torno de 470 reais e. Kirchner, Saidelles e Stumm (2009) apontam que é comum que os catadores de materiais recicláveis desenvolvem esta atividade por estarem desempregados.

\subsection{Adesão pelo trabalho de catador}

Os catadores de materiais recicláveis "optam" por esta atividade devido à dificuldade de inserção no mercado de trabalho, causada, muitas vezes, por questões como idade, condição social e baixa escolaridade (KIRCHNER; SAIDELLES; STUMM, 2009). É difícil afirmar sobre a existência de uma opção do trabalhador em ser catador de material reciclável, tal como colocou Rios (2008), motivo pelo qual se prefere o termo adesão. Godoy (2005) expõe que os catadores de materiais recicláveis são grupos de trabalhadores que estão presentes em todos os grandes centros ao redor do mundo e que, por diversos motivos, aderiram a esta profissão. 
Antes de se tornar um catador de materiais, os entrevistados comentaram ter tido trabalho com carteira assinada em indústria local e ter trabalhado como pedreiro e lavrador. A maioria dos catadores autônomos trabalhou em outro emprego antes da atividade de catação. Sobre a "opção" em ser catador, observa-se que algumas pessoas começaram a trabalhar com materiais recicláveis por necessidade, já que não possuíam nenhum tipo de renda e essa era uma forma de se sustentarem.

Os catadores autônomos aderiram a esta atividade por ser mais leve e mais fácil, tendo em vista a existência de alguns problemas de saúde, como aponta o Catador A: "Fiquei doente e, para pegar serviço pesado, eu não aguento, por isso eu comecei". Outro catador autônomo optou trabalhar com materiais recicláveis por não querer ter chefe, preferindo ter seu próprio emprego e sua própria jornada de trabalho: "Cansei de ser mandado pelos outros, trabalho a hora que eu quero" (Catador H). São vários os motivos que os levaram a serem catadores, destacando-se a necessidade.

\subsection{Meio ambiente}

Com a aceleração dos processos de industrialização, urbanização e crescimento demográfico, ocorreu um aumento tanto em quantidade quanto em diversidade da produção de resíduos sólidos, que passaram a ter em sua composição elementos sintéticos e perigosos à saúde e ao meio ambiente (FIGUEIREDO, 1995; RIGOTTO, 2002). Dessa forma, Michels et al. (2004) ressaltam que os catadores desempenham um papel fundamental na cadeia dos resíduos sólidos, pois são responsáveis pela coleta e destinação correta desses resíduos. Sobre a relação dos resíduos sólidos com o meio ambiente, os catadores autônomos relataram que se trata de problema ambiental. O Catador I disse que "Faz mal para o meio ambiente", e apenas um dos catadores autônomos disse não saber da relação entre meio ambiente e resíduos sólidos.

Quando questionados se a profissão de catador de material reciclável contribui para o meio ambiente, a concordância foi unânime. Todos os catadores autônomos têm a consciência de que seu trabalho contribui diretamente para com o meio ambiente, como explicam o Catador $\mathrm{H}$, "Sim, tira das ruas o lixo", e o Catador A, "Acho que sim, pois está limpando o meio ambiente". Gouveia (2012) ressalta que estas pessoas que trabalham com materiais recicláveis são considerados os protagonistas da indústria de reciclagem, pois, além de deterem uma posição fundamental na gestão de resíduos sólidos, realizam um papel de suma importância para o meio ambiente.

\subsection{Saúde e riscos}

Buscou-se saber a percepção dos catadores quanto ao que é ter saúde, porém alguns acharam esta pergunta um tanto quanto complexa. Os catadores autônomos definiram saúde como algo bom para eles, que inclui sempre estar em condições de exercer sua profissão, como relatou o Catador H: "É estar bem e ter condições de trabalhar". A exposição da saúde humana e ambiental a certos agentes danosos pode ocorrer de duas formas: de modo direto, quando há algum contato entre o ser humano e agentes patogênicos, ou de modo indireto, quando há alguma amplificação de um fator de risco, que age de forma descontrolada sobre tudo que está em volta (CAVALCANTE; FRANCO, 2007).

Perguntou-se, então, sobre sua opinião a respeito dos riscos que o trabalho de catação possui. Por ser um trabalho de contato direto com diversos tipos de materiais, os trabalhadores podem acabar se contaminando com alguma substância ou até mesmo serem feridos por algum material cortante. Os catadores autônomos afirmam que este tipo de trabalho possui algum risco à sua saúde, como cortes, queda da carroça e contato com materiais contaminados. Isso fica claro 
nas seguintes falas: "Acho que sim, pegar qualquer coisa com a mão acaba se cortando" (Catador A); e, "Sim, pode cair um ferro e machucar, pode cair da carroça e machucar" (Catador H).

O trabalho de catador pode gerar riscos à saúde, como apontam Ferreira e Anjos (2001), pois, ao procurarem em resíduos vazados materiais recicláveis, estas pessoas estão expostas à contaminação presente nos resíduos, bem como a riscos à sua integridade física em função do manuseio. Outro fator a ser mencionado são os objetos perfurantes e cortantes, que são os principais agentes de riscos encontrados. Por serem catadores autônomos, não há investimentos em equipamentos de proteção individual (EPI's), como aventais, luvas, máscaras e chapéus.

\subsection{Dificuldades da profissão}

As dificuldades encontradas pelo catador nesta profissão são muitas. Alguns disseram que não possuem nenhuma dificuldade na profissão de catador de materiais recicláveis, porém outros falaram sobre as condições do trabalho e sobre o preço pago pelos materiais. Os entrevistados relataram que o preço dos materiais é muito barato tendo em vista o esforço necessário à coleta: "Sol quente e pagam pouco pelo material" (Catadora I); e "Pagam muito pouco pelo material" (Catador $\mathrm{H})$.

Os catadores enfrentam certas dificuldades, como a falta de um sistema de remuneração; a instabilidade de renda devido às flutuações dos preços dos materiais e ao volume de materiais recolhidos; e a baixa capacidade administrativa por parte das organizações de catadores (IPEA, 2010). Sobre a competição entre os catadores, apenas um dos catadores entrevistados afirmou que há competição, principalmente com o pessoal da cooperativa existente.

\subsection{Melhorias no trabalho}

Foi perguntado se o trabalho de catador poderia ser melhorado. Os catadores autônomos relacionaram tais melhorias com uma prática de melhor preço, pois acreditam que os compradores deveriam pagar mais pelos materiais, fato apontado pelos Catadores $\mathrm{E}, \mathrm{H}$ e I. Por outro lado, o Catador A afirmou que não como é possível ter melhorias no trabalho de catador.

Os catadores podem ser vistos como vendedores, que, para Souza (1999), consiste em um tomador de preço. Contudo, o catador não exerce influência sobre o preço, uma vez que simplesmente aceita o montante já estabelecido. Empiricamente, os catadores são tomadores de preço, havendo, ainda, a figura do intermediário (atravessadores), que negocia diretamente com os catadores.

Sobre a vida do catador, perguntou-se se houve melhora durante os últimos cinco anos. Os catadores autônomos relataram que sua vida melhorou um pouco, mas relatam a falta do reconhecimento do trabalho e o preço baixo pago pelos materiais. Os catadores não citaram aspectos ambientais. Ainda que não apontada pelos catadores, é importante ressaltar a Lei $\mathrm{n} . \underline{\mathrm{o}}$ $12.305 / 2010$, que beneficia os trabalhadores da catação, assegurando os direitos dos catadores e das cooperativas de materiais de reciclagem, a fim de que as cidades e empresas geradoras de resíduos sólidos os destinem corretamente, não fazendo o descarte no meio ambiente e reaproveitando o que for possível (BRASIL, 2010).

\subsection{Visão sobre quem é o catador}

Questionou-se a percepção dos catadores em relação ao que as outras pessoas pensam sobre o seu trabalho. Nesse sentido, os catadores autônomos relataram que algumas pessoas os confundem com lixeiros e que outras pessoas os acham sujos. O preconceito existente por 
parte dos cidadãos da cidade local é visível, como aponta o Catador A: "O preconceito é o que mais existe, uns acham ruim [a nossa atividade], outros acham bom". A esse respeito, Medeiros e Macêdo (2006) expõem a falta de reconhecimento da sociedade em relação aos catadores, por serem pessoas que vivem em situações precárias.

Foi perguntado sobre quem é o catador de materiais recicláveis. A maioria dos catadores autônomos não soube responder. Os catadores que responderam abordaram que o catador de recicláveis consiste nas pessoas que ajudam a limpar as ruas, retirando todo o material reciclável: "O que ajuda a limpar" (Catador A); e "Nós que tiramos das ruas os lixos" (Catador H).

Os catadores são considerados os principais agentes da indústria de reciclagem, pois exercem uma posição fundamental na gestão de resíduos sólidos. São responsáveis pela redução do acúmulo de lixo e por escoarem os materiais que fomentam as grandes indústrias de reciclagem, retirando do meio ambiente grandes quantidades de resíduos sólidos (GOUVEIA, 2012; MICHELS et al., 2004).

\subsection{Discussão}

Cidadania é um status concedido para aqueles que são membros integrais de uma comunidade, tendo os mesmos direitos e deveres. Contudo, algumas pessoas não possuem tais direitos, sendo marginalizadas ou até mesmo excluídas da vida social e da tomada de decisão (MARSHALL, 1967; DALLARI, 2004). A realidade dos catadores autônomos demonstra que há diversos riscos e problemas, como o perigo de se cortar com algum material cortante ou até mesmo de se contaminar com alguma substância presente nos resíduos sólidos coletados, devido à falta do uso de EPI's. Outros problemas citados pelos catadores autônomos são os fatores climáticos e a não separação dos materiais.

Por não estarem organizados em forma de cooperativa, o poder de barganha destes trabalhadores é menor diante dos atravessadores que compram seus materiais por um preço abaixo do mercado e revendem novamente mais tarde por um preço maior. Outros pontos importantes relatados por eles são a ausência do suporte do poder público, a falta de apoio de parceiros e o não reconhecimento e a não valorização do seu trabalho pela população. Isso reforça a importância de os catadores se organizarem coletivamente, em especial na forma de cooperativa, uma vez que a economia solidária auxiliaria no processo de efetivação do exercício da cidadania dos catadores.

Os catadores, quando organizados coletivamente, ao longo da construção de uma cooperativa, passam a serem sujeitos de direitos (DIAS, 2002). Para Gomes (s/d), uma cooperativa faz com que as pessoas passem a exercer sua cidadania, afastando o estigma negativo da atividade e oferecendo melhores condições de trabalho e reconhecimento social. Segundo Singer (2002), uma cooperativa implica aos seus membros os conceitos que garantem igualdade e democracia entre eles na condução da entidade: um voto por cabeça, sua autoridade suprema investida na assembleia geral dos sócios e todos os sócios tendo a mesma cota do capital da cooperativa. Magera (2005) explica que as cooperativas de reciclagem são associações de pessoas que se unem, deliberadamente, para alcançar seus objetivos nas áreas econômica, social e cultural.

Para Godoy (2005), uma cooperativa de catadores é uma iniciativa de formalização e inclusão social de uma parcela da população que é caracterizada pela baixa qualificação profissional e extrema pobreza. O mercado de materiais recicláveis é composto de mais diversos níveis (catadores; depósitos de ferro-velho; pequenos, médios e grandes sucateiros; e indústria recicladora). Gomes (s/d) expõe, ainda, que a organização coletiva dos catadores é uma alternativa viável, uma vez que individualmente são explorados pelos atores da cadeia produtiva. O catador, na cadeia produtiva dos materiais recicláveis, ocupa a pior e menos rentável posição da cadeia. 


\section{CONCLUSÃO}

A cidadania é entendida como os direitos e as obrigações que um indivíduo tem com a sociedade em que vive para que esta possa garantir o bem-estar de todos que a habitam. Por meio desta pesquisa, pode-se constatar que nem todos são detentores desses direitos: os catadores são pessoas de baixa renda que buscam na profissão de catador de materiais recicláveis uma fonte de renda.

A colônia de catadores é um lugar sem estrutura básica (asfalto e esgoto) e de difícil acesso. A idade média destes catadores varia entre 49 e 70 anos, possuindo uma renda mensal de $\mathrm{R} \$ 300,00$ a $\mathrm{R} \$ 600,00$. Por serem pessoas de baixa renda, viram na reciclagem uma forma de ganharem seu sustento. Alguns dos catadores iniciaram nesta profissão por ser um serviço mais "leve", por terem algum problema de saúde e não aguentarem carregar peso ou trabalhar em outro serviço mais pesado. Outro fator que alguns citaram é que não queriam ser mandados por outras pessoas, mas ter seu próprio emprego.

Em relação aos danos ao meio ambiente, os catadores autônomos têm a consciência de que o lixo descartado de forma incorreta afeta de alguma forma o meio ambiente. Sobre a questão da saúde, os catadores definiram-na como ter condições de exercer seu trabalho, alegando que toda profissão possui seus riscos. O risco na profissão de catador está relacionado com o perigo de se cortar com algum tipo de material ou de se contaminar com alguma substância tóxica presente nos materiais coletados.

O reconhecimento da sociedade ainda é um problema para os catadores autônomos, pois esta os vê como pessoas sujas e não dignas, ainda que a profissão seja reconhecida pela CBO. Os catadores sabem de sua importância e sabem quem são eles que retiram das ruas os materiais recicláveis para ganharem seu sustento. Como em qualquer profissão, há certas dificuldades, porém a principal identificada foi o preço que os atravessadores pagam pelos materiais. Por não serem reunidos em forma de cooperativa, os catadores perdem poder de barganha diante dos atravessadores.

A organização coletiva fortaleceria sua identidade como catador. Nesse sentido, observa-se que a criação do Movimento Nacional dos Catadores de Materiais Recicláveis (MNCR), a instituição da PNRS, a inclusão do catador de material reciclável na $\mathrm{CBO}$ e, principalmente, a organização coletiva, em forma de cooperativa de reciclagem, contribuem para o exercício da cidadania dos catadores.

Este estudo fica limitado ao contexto do grupo de catadores analisado e, portanto, não pode ser generalizado. Para trabalhos futuros, seria interessante realizar: 1) um estudo históricosocial sobre a formação desta "Colônia de Catadores"; e 2) uma comparação entre os catadores autônomos e os catadores cooperados. 


\section{REFERÊNCIAS}

BRASIL. Lei n. 12.305, de 02 de agosto de 2010. Institui a PNRS - Política Nacional de Resíduos Sólidos. Disponível em: <http://www.planalto. gov.br/ccivil_03/_ato2007-2010/2010/lei/ |12305.htm>. Acesso em: 30 jul. 2013.

BRASIL. Ministério do Trabalho. Classificação Brasileira de Ocupações (СBO): trabalhadores da coleta e seleção de material reciclável. Disponível em: <http://www.mtecbo.gov.br/ index.htm>. Acesso em: 30 maio 2014.

CAVALCANTE, Sylvia; FRANCO, Márcio Flávio Amorim. Profissão perigo: percepção de risco à saúde entre os catadores do Lixão do Jangurussu. Revista Mal-Estar Subjetividade, Fortaleza , v. 7, n. 1, p. 211-231, mar. 2007. Disponível em: <http://pepsic.bvsalud.org/ scielo.php? script=sci_arttext\&pid=S1518$61482007000100012 \&$ lng $=p t \& n r m=i s o>$. Acesso em: 17 jun. 2014.

COLLIS, Jill; HUSSEY, Roger. Pesquisa em administração: um guia prático para alunos de graduação e pós-graduação. 2. ed. Porto Alegre: Bookman, 2005.

COOPER, Donald R.; SCHINDLER, Pamela S. Métodos de pesquisa em administração. 10. ed. Porto Alegre: Bookman, 2011.

COUTINHO, Carlos Nelson. Cidadania e modernidade. Perspectiva: Revista de ciências sociais, São Paulo, n. 22, p. 41-59, 1999. Disponível em: <http://200.145.78.103/ perspectivas/article/view/2087/1709>. Acesso em: 20 ago. 2012.

DALLARI, Dalmo de Abreu. Direitos humanos e cidadania. 2. ed. São Paulo: Moderna, 2004.

DIAS, Sonia Maria. Lixo e cidadania: os impactos da política de resíduos sólidos de Belo Horizonte no mundo do trabalho do catador da ASMARE. In: ENCONTRO DA ASSOCIAÇÃO BRASILEIRA DE ESTUDOS POPULACIONAIS, 13., 2002, Ouro Preto. Anais... Ouro Preto: Minas
Gerais, 2002. Disponível em: <http://www. abep.nepo.unicamp.br/docs/anais/pdf/2002/ GT_MA_ST37_Dias_texto.pdf $>$. Acesso em: 24 abr. 2014.

DUARTE, Rosália. Pesquisa qualitativa: reflexões sobre o trabalho de campo. Cadernos de pesquisa, São Paulo, n. 115, p. 139-154, mar. 2002.

FERREIRA, João Alberto; ANJOS, Luiz Antonio dos. Aspectos de saúde coletiva e ocupacional associados à gestão de resíduos sólidos municipais. Cadernos de saúde pública, v. 17, n. 3, p. 690-696, 2001. Disponível em: <http:// www.scielosp.org/pdf/csp/v17n3/4651.pdf>. Acesso em: 12 fev. 2014.

FIGUEIREDO, Paulo Jorge Moraes. A sociedade do lixo: os resíduos, a questão energética e a crise ambiental. Piracicaba: UNIMEP, 1995.

GODOY, Tatiane Marina Pinto de. 0 espaço da produção solidária dos catadores de materiais recicláveis: usos e contradições. 2005. 150 f. Dissertação (Mestrado em Geografia) Universidade do Estadual Paulista, Rio Claro, 2005. Disponível em: <http://neccbrasil.com. br/pdf_pesquisa/O_espaco_da_producao_ solidaria_dos_catadores.pdf $>$. Acesso em: 22 nov. 2013

GOMES, Luiz Cláudio Moreira. Lixo \& cidadania: catadores de materiais recicláveis do Aterro Metropolitano de Jardim Gramacho. Florianópolis: CONPEDI, [s/d]. Disponível em: $<$ http://www.publicadireito.com.br/conpedi/ manaus/arquivos/anais/recife/trabalho_ justica_luiz_claudio_gomes.pdf $>$. Acesso em: 10 maio 2014.

GONÇALVES, Cleber Vaz et al. A vida no lixo: um estudo de caso sobre os catadores de materiais recicláveis no município de Ipameri, GO. Holos, ano 29, v. 2, p. 238-250, 2013. Disponível em: <http://www2.ifrn.edu.br/ ojs/index.php/HOLOS/article/view/841/673>. Acesso em: 20 jan. 2014. 
GOUVEIA, Nelson. Resíduos sólidos urbanos: impactos socioambientais e perspectiva de manejo sustentável com inclusão social. Revista ciência \& saúde coletiva, Rio de Janeiro, v. 17, n. 6, p. 1503-1510, 2012. Disponível em: <http://www.redalyc.org/ pdf/630/63023390015.pdf>. Acesso em: 16 jan. 2014.

GRECHONIAK, Marilu Teles; BORDIGNON, Nara Fernandes. Direitos humanos e cidadania. Revista FAPIC, v. 1, n. 1, 2011. Disponível em: <http://201.20.178.202:8088/fapi/index.php/ FAPIC/article/view/68>. Acesso em: 20 ago. 2012.

INSTITUTO DE PESQUISA ECONÔMICA APLICADA (IPEA). Relatório de pesquisa: pesquisa sobre pagamento por serviços ambientais urbanos para gestão de resíduos sólidos. Brasília: IPEA, 2010. Disponível em: <http://www.ipea.gov.br/portal/images/ stories/PDFs/100514_relatpsau.pdf>. Acesso em: 15 jun. 2014.

KIRCHNER, Roseane Maria; SAIDELLES, Ana Paula Fleig; STUMM, Eniva Miladi Fernandes. Percepções e perfil dos catadores de materiais recicláveis de uma cidade do RS. Revista brasileira de gestão \& desenvolvimento regional, Taubaté, v. 5, n. 3, p. 221-232, set./dez. 2009. Disponível em: <http:// rbgdr.net/revista/index.php/rbgdr/article/ view/257/165>. Acesso em: 12 set. 2012.

MAGERA, Márcio. A reciclagem dos resíduos sólidos urbanos e o uso das cooperativas de reciclagem - uma alternativa aos problemas do meio ambiente: juventude, educação e cooperativismo. In: ENCONTRO DE PESQUISADORES LATINO-AMERICANOS DE COOPERATIVISMO, 5., 2008, Ribeirão Preto, Anais... São Paulo: Fundace. Disponível em: <http://www.fundace.org.br/cooperativismo/ arquivos_pesquisa_ica_la_2008/043-magera. pdf>. Acesso em: 15 nov. 2012.

MAGERA, Márcio. Os empresários do lixo: análise interdisciplinar das cooperativas de reciclagem de lixo. 2. ed. Campinas: Átomo, 2005.

MARSHALL, Thomas Humphrey. Cidadania, classe social e status. Rio de Janeiro: Zahar Editores, 1967.

MEDEIROS, Luiza Ferreira. Rezende; MACÊDO, Kátia Barbosa. Catador de material reciclável: uma profissão para além da sobrevivência? Psicologia \& sociedade, Porto Alegre, v. 18, n. 2, ago. 2006. Disponível em: <http://www.scielo.br/pdf/psoc/v18n2/08. pdf $>$. Acesso em: 13 set. 2012.

MICHELS, Ido et al. Resíduos sólidos urbanos. Campo Grande: Editora UFMS, 2004.

MORAES, Roque. Análise de conteúdo. Revista de educação, Porto Alegre, ano 22, n. 37, p. 7-32, mar. 1999.

RIGOTTO, Raquel Maria. Produção, consumo, saúde e ambiente. In: MINAYO, Maria Cecília de Souza; MIRANDA, Ary Carvalho de (Orgs.). Saúde e ambiente sustentável: estreitando nós. Rio de Janeiro: Fiocruz, 2002. p. 233-260.

RIOS, Cristiane Margarete. Lixo e cidadania: um estudo sobre catadores de recicláveis em Divinópolis-MG. 2008. 80 f. Dissertação (Mestrado Educação, Cultura e Organizações Sociais) - Universidade do Estado de Minas Gerais, Divinópolis, 2008.

RODRIGUES, José. Qual cidadania, qual democracia, qual educação? Trabalho, educação \& saúde, Rio de Janeiro, v. 4, n. 2, p. 417-430, set. 2006. Disponível em <http:// www.scielo.br/pdf/tes/v4n2/12.pdf >. Acesso em: 22 nov. 2012.

SEVERINO, Antonio J. Educação, trabalho e cidadania: a educação brasileira e o desafio da formação humana no atual cenário histórico. São Paulo em perspectiva, São Paulo, v. 14, n. 2, p. 65-71, jun. 2000. Disponível em: <http:// www.scielo.br/pdf/spp/v14n2/9790.pdf >. Acesso em: 22 nov. 2012. 
SINGER, Paul Israel. Introdução à economia solidária. São Paulo: Fundação Perseu Abramo, 2002.

SOARES, Maria Victoria de Mesquita Benevides. Diretos humanos e cidadania. São Paulo: Instituto de estudos avançados da Universidade de São Paulo, [s/d]. Disponível em: <http://www.iea.usp.br/publicacoes/ textos/benevidescidadaniaedireitoshumanos. pdf/at_download/file>. Acesso em: 16 jan. 2014.

SOUZA, Ernâni Lúcio Pinto de. A organização industrial do setor madeireiro no município de Sinop, Mato Grosso: uma análise da estrutura de mercado. 1999.126 f. Dissertação (Mestrado em Planejamento do Desenvolvimento) Universidade Federal do Pará, Belém, 1999.

STROH, Paula Yone; SANTOS, Michaela de Araújo. Lixo, trabalho e cidadania. Latitude, v. 1, n. 2, p.135-150, 2007. Disponível em: <http://www.seer.ufal.br/index.php/latitude/ article/view/82/pdf_7>. Acesso em: 15 abr. 2014.

TENÓRIO, Fernando Guilheçrme; ROZENBERG, Jacob Eduardo. Gestão pública e cidadania: metodologias participativas em ação. Revista de administração pública, v. 31 , n. 4, p 101-125, 1997. Disponível em: <http:// bibliotecadigital.fgv.br/ojs/index.php/rap/ article/view/7882/6551>. Acesso em: 16 jan. 2014.

VIEIRA, Arlete Candido Monteiro; RICCI, Fábio. Cooperativas populares de reciclagem e a articulação entre geração de renda e gestão ambiental. In: SIMPÓSIO DE EXCELÊNCIA EM GESTÃO E TECNOLOGIA, 6., 2008, Resende. Anais... Resende: AEDB, 2008. Disponível em: $\quad$ http://www.ww.w.aedb.br/seget/ artigos08/275_275_Cooperativas_Populares_ de_Reciclagem_-_Seget_2008.pdf>. Acesso em: 16 jan. 2014

YIN, Robert. K. Estudo de caso: planejamento e métodos. 4. ed. Porto Alegre: Bookman, 2010. 